\title{
Student help-seeking attitudes and behaviors in a digital era
}

Adnan Qayyum(1)

Correspondence: adnan@psu.edu College of Education, Pennsylvania State University, 305A Keller Building, University Park, PA 16802, USA

\begin{abstract}
This study examines college students' attitudes and habits for seeking academic help. Students preferences for seeking academic help via digital and non-digital technologies are identified $(N=438)$. Students' attitudes about seeking help are also analyzed. Factor analysis results indicate six attitudinal factors motivated students to seek help from peers and instructors: students' perceived usefulness of their peers; trust of peers; their perception of instructors; preference to work independently; overall perception of the course; and, perceived threat (i.e. sense of vulnerability about their ability). Overwhelmingly, students prefer to seek help from classmates rather than instructors. Due to the cohort model of the programs -where students take all or most their courses with the same students throughout the program- they seek help more in person than via using digital resources (texting, social media). Multiple linear regression analysis indicates that perceived threat, perception of instructors, and students' preference to work independently, are significant in predicting whether students sought help from instructors outside of class. Implications of these findings are discussed.
\end{abstract}

Keywords: Help-seeking, Learning strategies, Student motivations

\section{Introduction}

When students send instructors an email or a write post on a learning management system like Moodle or Canvas asking to clarify a course assignment, this is a form of helpseeking. Students can seek academic and non-academic help. Non-academic help seeking includes students reaching out for administrative, technological or counselling help. A student-initiated text message or Facebook post about course content to a classmate is a form of academic help-seeking. Academic help-seeking is one among many learning strategies students use to improve their learning, including studying more, organizing one's studying, note-taking, outlining notes and readings, reviewing, choosing engaging assignments, and managing expectations including lowering aspirations. Academic helpseeking is an important behavior that can allow face-to-face and online students to be more successful learners. Academic help seeking is the process of becoming aware of the need for help, deciding one needs help, identifying helpers, eliciting help, and evaluating the help (Aleven, Stahl, Schworm, Fischer, \& Wallace, 2003, p. 281; Cheng \& Tsai, 2011). Academic help-seeking can be considered a self-regulation learning strategy (Newman, 1994). Just as self-regulation requires exerting more control over one's life, self-regulated learning is about how students become masters of their own learning process

(c) The Author(s). 2018 Open Access This article is distributed under the terms of the Creative Commons Attribution 4.0 International License (http://creativecommons.org/licenses/by/4.0/), which permits unrestricted use, distribution, and reproduction in any medium, provided you give appropriate credit to the original author(s) and the source, provide a link to the Creative Commons license, and indicate if changes were made. 
(Zimmerman, 1990). However, authors of the well-used self-regulated learning instrument, the Motivated Strategies for Learning Questionnaire (Pintrich et al., 1988) have stated that most work on self-regulated learning has simply overlooked help-seeking as an important learning strategy. Indeed, one of the authors concedes help-seeking may be one of the most useful learning strategies students' use (McKeachie, 2006).

Academic help-seeking can be both formal and informal (Karabenick \& Knapp, 1988). Formal help seeking is when students ask questions in class or when they contact instructors or academic student services for help outside of class. Informal help seeking is also outside of class, but when students turn to classmates, other peers, friends, work colleagues or even an instructor who is not the course instructor. The focus of this research is why students seek academic help outside of class, and in particular, what motivates them to seek both formal and informal help from classmates and instructors. Focusing on the motivation for help-seeking can provide insights about when students' academic help-seeking may be useful and should be fostered.

\section{Background and research questions}

For informal help-seeking, older research (Karabenick \& Knapp, 1988, p.225) shows that overall, most students (approximately 70\%) used at least one informal source for help-seeking, such as peers, and used at least one formal source, such as academic student services (62\%). However, during a course students are more likely to turn to other students (63\%) or classmates (57\%) than instructors (47\%).

Whether a student seeks help can be affected by student-related factors and system related factors (Aleven et al., 2003). Student-related factors include age, gender, the student's self-esteem, meta-cognitive skills, prior knowledge of the subject domain and the learning environment.

Research on student-related factors like self-esteem indicates that students with lower self-esteem were less likely to seek help. Specifically, students were less likely to seek help if they already felt vulnerable about their knowledge or ability in a course. Concern about self-esteem was inversely related to students' formal help-seeking tendencies $(r=-.28, p<.001)$ and informal help-seeking tendencies $(r=-.13, p<.01)$ (Karabenick \& Knapp, 1991, p.224). Perceived threat to students' self-esteem also made a difference in how often they sought help. There may be a strong negative relationship between perceived threat and formal help-seeking $(r=-.48)$. These results by Kitsantas and Chow are consistent with other research $(r=-.28)$ suggesting that students may prefer to seek help informally partly because it is less threatening than formal channels are (Karabenick \& Knapp, 1991). Age is another personal factor that has been studied in relation to help-seeking. Dunn, Rakes, and Rakes (2014) found in a study of distance education students, there was an inverse relationship between age and help-seeking. Older students were less likely to seek help than younger students.

System-related factors are attributes of the help-seeking environment, including the course goals, whether the feedback provided to students is stated in concrete or abstract terms, how interactive the feedback is particularly for technology-based help spaces such as course management systems, whether the type of feedback is a wellscaffolded list of steps or explanations of how something works (Aleven et al., 2003, p. 294) and class goals. 
For the purpose of help-seeking, student goals have been classified into two major types: instrumental and executive help-seeking (Nelson-Le Gall \& Resnick, 1998). The goal of executive help seeking is short-term, with a focus on completing specific tasks. Instrumental help-seeking has a deeper goal of improving understanding or learning. For example, Kitsantas and Chow (2007) found that the goal of the class affects students help-seeking behavior. Task-focused classes increased the likelihood of students' seeking help, whereas achievement focused classes decreased the likelihood of students' seeking help. This suggests that students may be more likely to seek executive help than instrumental help.

The research varies on the differences in help-seeking by online and face-to-face students. Mahasneh, Sowan, and Nassar (2012) found that contrary to expectations students online asked for help less frequently than face-to-face classrooms students. Although the findings were purely descriptive and a have a large standard deviation, face-to-face classrooms students $(\mathrm{M}=7.1, \mathrm{SD}=6.9)$ asked for help far more often than students online $(\mathrm{M}=2.4, \mathrm{SD}=2.5)$. This challenges earlier research that suggests online students felt less threatened in seeking help than students in fully face-to-face classrooms (Kitsantas \& Chow, 2007). Chi-square analysis indicated there were significant differences in amount of threat felt, depending on the communication approach $\left(x^{2}(12)=82.50, p<.001\right)$. Contacting instructors via email or the course management system (CMS) was preferred over seeking help in person or via phone. There were also significant differences in communication approaches that students were likely to use for informal help-seeking $\left(\mathrm{X}^{2}(12)=89.48, p<.001\right)$. Again, more students preferred to use ICTs (information and communication technologies, like email or CMS) to contact classmates for help $(f=301)$ than in person $(f=119)$ or by phone $(f=54)$.

There was a significant difference, $F(3,470)=110.21, p<.001)$, for how threatened students felt about seeking help in three different learning environments: face-to-face classes, a distributed class which had face-to-face and a web component, and asynchronous distance education (Kitsantas \& Chow, 2007). Post hoc Tukey tests revealed that students in traditional classes felt more threatened in seeking help $(M=3.07)$ than students in the distributed class $(M=1.63, p<.001)$. Students in traditional classrooms also felt more threatened than students in the distance education (DE) courses that had only synchronous interaction $(M=1.37, p<.001)$, and a DE course with both synchronous and asynchronous interaction $(M=1.49, p<.001)$.

In a study of online students $(N=26)$, perhaps unsurprisingly, students preferred using digital technologies to seek help from both instructors and fellow students. Nearly all students preferred method to contact instructors was by email (92.3\%) when seeking help about subject matter content. Less common was calling via phone (19.2\%) and posting a question on the class discussion board (15.4\%). Live chat and face-to-face meeting was very seldom used (Koc \& Liu, 2016). A majority of students preferred method to contact classmates by email $(53.8 \%)$ for help about subject matter content but also a third of students posted a question on the class discussion board (30.8\%), called classmates (15.4\%) or met them face to face (15.4\%).

However, research on students approach to seeking help via digital technologies is based on a small sample and does not include students taking courses on campus. Among all the research, there is none about how students attitude toward helpseeking affects their academic help-seeking behavior. Thus, research questions for this study were: 
1. How did on-campus students contact peers and instructors when seeking help?

2. What attitudinal factors motivate students to seek academic help?

3. Can attitudinal factors help predict help-seeking behavior?

\section{Method}

The study was conducted at a post-secondary college in Canada. The college has a range of applied programs, some of which included a substantial amount of cohort classes and group work (e.g. Business, Engineering), and others that did not (e.g. Computing). The cohort model is when students take all or most their courses in the program with the same group of students. Students there could decide if and how to seek academic help. Data was gathered with support of the institutional planning office at the college.

Survey design method was used to explore students' attitudes and behavior about seeking academic help. The survey was designed using a three-step process. First, the survey was created based on interviews at the research site and existing relevant surveys on academic help seeking. Second, the survey was pilot tested at a different Canadian university for reliability and validity. Finally, the survey was administered at the college.

\section{Survey design}

Initially, interviews were conducted at the research site to identify key themes about students' study habits, including help-seeking. During the interviews, students were asked five open-ended questions about: how they communicate with classmates; for what purposes; how they communicate with instructors; for what purposes; and what they do if they have a problem or issue in a course. Twenty-nine interview sessions were held with 69 students. A convenience sample was used based on who was willing to participate.

Interview data indicated that classmates, outside of class, were a source of courserelated information, feedback, resources and motivation. Students help-seeking with classmates ranged from: a) incidental conversations between classes to; b) more intentionally communicating about specific course content, notes, assignments, resources and administrative questions to; c) studying together in loosely structured groups to; d) collaborating on and reviewing assignments with peers. Students did this in-person as well as using texting, social media, email, calling on mobile phones and using the course management system.

If and how students asked classmates for help was shaped by a mix of system-related and personal factors. System related factors included how the program was designed (e. g. group work was commonly required and practiced in the program), how specific courses were designed and the knowledge domain of a subject area (e.g. Calculus or Creative Writing). For personal factors, there were two dimensions: attitudinal and behavioral. Attitudinal dimensions included whether a student trusted their peers, their opinions about how useful and reliable peers were, and their perception about how available, approachable and knowledgeable instructors were. These attitudinal factors seemed to influence the behavior, which included whether students turned to classmates and instructors for help outside of class time. 
Based partly on these results the survey was designed. The attitudinal and behavioral items derived mainly from the interview results and from articles discussed in the literature review, particularly research on help-seeking (Karabenick and Knapp's 1988); Karabenick (2011); help-seeking and perceived threat (Kitsantas \& Chow's, 2007), virtual hallways (Nicholson's, 2002), student interaction patterns (Picciano's, 2002), the Motivated Strategies for Learning Questionnaire (Pintrich et al., 1988), and the Classroom Community Scale (Rovai, 2002).

For content validity, survey items were reviewed for relevance and clarity. Five researchers and practitioners in education, uninvolved in the research, reviewed the survey. They were asked to rank and judge the questions for clarity and relevance to the topic of each section of the survey. These topics were indicated in explanatory notes throughout the survey.

The instrument included groups of items to measure the two personal attributes identified in the interviews; "trust of peers" and "perception of instructors". These measures have been called "attributes" rather than "constructs". In doing so, a more conservative definition of constructs is being used. Attributes indicate how a person feels, behaves or thinks (Creswell, 2011). Constructs are groups of items used to measure an attribute indirectly (Cronbach \& Meehl cited in Lissitz \& Samuelsen, 2007, p.439). Indirect measures are being used in this research, such as "trust of peers" and "perception of instructors". However, constructs are usually indirect measures based on prior research. That is not the case with the indirect measures here. At best, the results of this study could be used as constructs in future research.

Several items were necessary to measure these attributes, as there were no direct measures of peer trust and perception of instructors. Peer trust had three dimensions: affective trust, reliability and timeliness of responses. The affective dimension of trust was the most difficult to operationalize. It included items based on existing research such as:

- I trust other students in this program.

- I feel isolated from other students in this program. (This was a negatively worded version of the item "I feel connected to others in this course". Both the positively and negatively worded items are on "Rovai's Classroom Community Scale" (2002)).

Measuring the reliability dimension of peer trust was more straightforward, with the following items used:

- I can rely on classmates to help me.

- I can rely on classmates to respond to my course questions quickly.

To measure the usefulness dimension of peer trust, the items included:

- I work with classmates because it helps me understand course content better.

- I work with classmates because it saves time.

- I work with classmates because it keeps me motivated to keep working.

- I work with classmates because classmates provide useful feedback for my work. 
To measure students' perception of instructors, the following items were used:

- Instructors are available when I have any question in a course.

- Instructors are approachable if I have any questions in a course.

- I don't want to look stupid so I don't ask instructors questions outside of class.

- I would not hesitate to ask an instructor for help.

For all scale items, behavioral and attitudinal, a Likert scale was used where the middle points were not defined, allowing the scale to be a true ratio scale. Students were also given a "Not Applicable" option on the Likert scale.

\section{Pilot-test}

The resulting survey was pilot-tested at a different Canadian university for usability and reliability of the instrument. Respondents $(N=40)$ were also asked to make comments and suggestions while completing the survey about the clarity and format of the survey.

Factor analysis was used to analyze if the items from the survey were associated with latent variables, called attributes, that are not as easy to directly measure. Overall, factor analysis of items found four attributes to measure students' attitudes of their study habits outside of class. The attributes "usefulness of peers" and "perception of instructor" (i.e. factor 1 and 2 respectively) were found and were consistent with the results of the interviews. Items for the other two attributes of peer trust -affective trust and reliability- clustered in a pattern together (i.e. factor 3). Not all of the original items loaded on this factor. The fourth factor was called "help seeking". The two items that loaded for this factor were originally included to measure student attitudes toward their program and toward their instructors respectively.

Factors three and four were retained as attributes (i.e. peer trust and conscious helpseeking). In the interviews used for the survey design, too fine a distinction may have been made when measuring the attribute "peer trust". The affective dimension of peer trust was separate from the reliability dimension. The observed patterns from the factor analysis show these two dimensions may be strongly related. This result suggests that peer trust can be measured, but different items need to be used than suggested from the interviews. The fourth factor, "conscious help-seeking", was from the research. The two items in this attribute were originally included to measure student attitudes toward their program and toward their instructors respectively.

Reliability analysis results showed acceptable levels of Cronbach alpha coefficient for the entire instrument ( 0.78 for 38 items) and for each attitudinal subscale, ranging from 0.81 to 0.89 .

\section{Administering the survey}

All students that participated in the main study were from second year and above to ensure students had some experience in the institution. Surveys were administered on site, in the classrooms.

A random sample of 27 courses of second year or above were chosen. Instructors were contacted to allow access to their courses for the study. From these 27 courses, 14 instructors agreed to allow for entry to survey students. From 14 courses a total of 449 surveys were completed. Univariate outlier analysis was conducted using Z scores. 
Multivariate outlier analysis was conducted by calculating Mahalanobis' distances. This was done by calculating multiple regression to a dummy variable (i.e. the survey number). There were no concerns for outliers. Correlations were calculated for all scaled survey items to test if any items might be multicollinear. No perfect or near perfect correlations were found among items so multicollinearity was not a concern. After all data were screened and cleaned, 438 surveys were usable.

\section{Results}

How did on-campus students contact peers and instructors when seeking help?

Students were asked about a broad range of communication options that they could use to contact peers or instructors for seeking help. They used messaging applications, social media and even phone to communicate with classmates. However, most students asked for help from classmates and peers by talking to them in person $(M=3.70)$. This was likely due to the large number of classes students had as a cohort in their programs, so they spent a lot of time together. Talking with classmates ranked highly because students were on campus regularly and saw classmates much of the time they were there. Surprisingly, talking via phone was slightly more common $(M=2.99)$ than text messaging $(M=2.87)$ and seeking help via Facebook $(M=2.20)$. The app used for messaging was not specified.

Most students asked for help from instructors by talking to them in person $(M=3.30)$. This was likely due to the large number of classes students had as a cohort in their programs, so they spent a lot of time together. The second most common format was by emailing instructors $(M=2.47)$. Using text messages $(M=1.16)$ and Facebook $(M=1.12)$ was quite uncommon for seeking help from instructors.

\section{What attitudinal factors motivate students to seek academic help?}

Factors were extracted for all attitudinal variables of the survey by using a cut-off point of 0.6 for loading factors. Variables were analyzed several times, with non-loading factors removed each time to help create a tighter model. After three iterations, all items loaded on a factor above an eigenvalue of one and before the point of inflection in the scree plot. During these analyses, varimax rotation was used. However, when oblique rotation was used, the factor correlation matrix (see Table 1) showed two factors, (factors 1 and 3), with a correlation of -.43 .

Table 1 Factor correlation matrix

\begin{tabular}{lllllll}
\hline Factor & $\begin{array}{c}\text { 1. Peer } \\
\text { usefulness }\end{array}$ & $\begin{array}{c}\text { 2. Perception of } \\
\text { instructors }\end{array}$ & $\begin{array}{r}\text { 3. Peer } \\
\text { trust }\end{array}$ & $\begin{array}{c}\text { 4. Independ- } \\
\text { ence }\end{array}$ & $\begin{array}{c}\text { 5. Perception } \\
\text { of course }\end{array}$ & 6. Threat \\
\hline 1. Peer Usefulness & 1.00 & & & & & \\
2. Perception of instructors & .07 & 1.00 & & & \\
3. Peer Trust & -.43 & -.15 & 1.00 & & \\
4. Independence & -.13 & .09 & .10 & 1.00 & \\
5. Perception of course & -.06 & -.29 & .05 & -.09 & 1.00 & .19 \\
6. Threat & .01 & -.27 & .09 & -.20 & 1.00 \\
\hline
\end{tabular}

Extraction Method: Principal Component Analysis Rotation Method: Oblimin with Kaiser Normalization 
There was $18 \%$ variance overlap between factors 1 (i.e. peer usefulness) and 3 (i.e. peer trust). This was not surprising as some researchers claim that orthogonal rotation "strains reality" as there is usually some relationship between factors (Tabachnick \& Fidell, 2012). Thus, an oblique rotation was chosen (i.e. oblimin) to ensure that only the unique relationship between each factor and observed variables was included in the model. The results of the tightest pattern matrix are in Table 2.

Table 2 Pattern matrix ${ }^{a}$ of attitudinal variables

\begin{tabular}{|c|c|c|c|c|c|c|}
\hline Factors & $\begin{array}{l}\text { 1. Usefulness } \\
\text { of peers }\end{array}$ & $\begin{array}{l}\text { 2. Perception } \\
\text { of instructors }\end{array}$ & $\begin{array}{l}\text { 3. Peer } \\
\text { trust }\end{array}$ & $\begin{array}{l}\text { 4. Indepen- } \\
\text { dence }\end{array}$ & $\begin{array}{l}\text { 5. Perception } \\
\text { of course }\end{array}$ & 6. Threat \\
\hline Eigenvalues & 5.28 & 3.11 & 1.67 & 1.39 & 1.06 & 1.01 \\
\hline Percentage of variance & 26.42 & 15.57 & 8.35 & 6.96 & 5.29 & 5.04 \\
\hline Cumulative percentage & 26.42 & 41.99 & 50.34 & 57.30 & 62.60 & 67.63 \\
\hline \multicolumn{7}{|l|}{ Questionnaire items } \\
\hline $\begin{array}{l}\text { Classmates help me understand } \\
\text { course content better }\end{array}$ & .753 & & & & & \\
\hline $\begin{array}{l}\text { Work w classmates because } \\
\text { I enjoy it }\end{array}$ & .685 & & & & & \\
\hline $\begin{array}{l}\text { Working w classmates results } \\
\text { in better work completed }\end{array}$ & .911 & & & & & \\
\hline $\begin{array}{l}\text { Working with classmates } \\
\text { saves time }\end{array}$ & .901 & & & & & \\
\hline $\begin{array}{l}\text { Working with classmates keeps } \\
\text { me motivated to keep working. }\end{array}$ & .812 & & & & & \\
\hline $\begin{array}{l}\text { Classmates provide useful } \\
\text { feedback for my work }\end{array}$ & .711 & & & & & \\
\hline $\begin{array}{l}\text { Instructors are available when } \\
\text { I have any questions. }\end{array}$ & & .811 & & & & \\
\hline Instructors are approachable & & .698 & & & & \\
\hline $\begin{array}{l}\text { Instructors in program } \\
\text { are knowledgeable }\end{array}$ & & .672 & & & & \\
\hline $\begin{array}{l}\text { I can rely on instructors to } \\
\text { respond to course questions } \\
\text { within a few hours. }\end{array}$ & & .771 & & & & \\
\hline $\begin{array}{l}\text { Trust other students in } \\
\text { the program }\end{array}$ & & & -.835 & & & \\
\hline Rely on classmates to help me & & & -.835 & & & \\
\hline $\begin{array}{l}\text { Rely on classmates to respond } \\
\text { to course questions within a few } \\
\text { hours }\end{array}$ & & & -.826 & & & \\
\hline $\begin{array}{l}\text { Enjoy discussing my ideas about } \\
\text { course content with other students }\end{array}$ & & & -.655 & & & \\
\hline $\begin{array}{l}\text { Prefer to do schoolwork on } \\
\text { my own }\end{array}$ & & & & .805 & & \\
\hline $\begin{array}{l}\text { Prefer to learn by trying things } \\
\text { for myself }\end{array}$ & & & & .854 & & \\
\hline $\begin{array}{l}\text { I feel this program has a } \\
\text { manageable workload. }\end{array}$ & & & & & -.872 & \\
\hline $\begin{array}{l}\text { I would recommend this } \\
\text { program to others. }\end{array}$ & & & & & -.722 & \\
\hline $\begin{array}{l}\text { Reverse of "Don't want to } \\
\text { look stupid" }\end{array}$ & & & & & & -.894 \\
\hline $\begin{array}{l}\text { I would not hesitate to ask } \\
\text { a instructor for help. }\end{array}$ & & & & & & -.741 \\
\hline
\end{tabular}


The pattern matrix yielded six factors with eigenvalues greater than one (ranging from 5.28 to 1.01) and before the scree plot flatlined. The six factors accounted for over two-thirds of variance in the measure (67.63\%). The structure matrix provided a useful double-check of factors extracted in the pattern matrix and also ensured shared variance among factors was not ignored. The same items load on the same factors in the structure matrix as in the pattern matrix.

The first factor comprised of items related to usefulness of seeking help from classmates and was shortened, in the tables, as "usefulness of peers". The second factor incorporated items related to students' "perception of instructors". The third factor comprised of items related to "peer trust". The fourth factor incorporated items about respondents' independence. The fifth factor incorporated items related to how respondents perceived their courses. For the sixth factor, items related to respondents' sense of threat and their willingness to seek help from instructors. This was labeled "threat" for short.

The first three factors, "usefulness of peers", "perception of instructors" and "peer trust" were consistent with attitudes students indicated in both the interviews and the pilot test of the survey. This would seem to indicate that students' opinions about the usefulness of working with classmates, their perception of instructors and their sense of how much they trust classmates may be important factors for why students sought informal help. However, it was unclear if there was a relationship between these attitudinal factors and students' actual behavior. Furthermore, it was uncertain if the factor model of attitudinal items could predict behavior. That is to say, did students' attitudes about their classmates and instructors relate to their help-seeking behavior?

\section{Can attitudinal factors help predict help-seeking behavior?}

Addressing this research question involved two analyses. The attitudinal factors from above were correlated with behavioral factors. This required conducting factor analysis of behavioral items and creating factor scores for both behavioral and attitudinal factors. Second, a regression model was created using the factor scores and correlation results.

\section{Correlation of attitude and behavior}

Assessing the relationship between attitudes and behavior involved creating factor scores for attitudinal variables, creating a factor model for behavioral variables, creating factor scores for behavioral variables and finally, correlating attitudinal and behavioral factor scores.

Factor scores were calculated for attitudinal variables using the Anderson-Rubin, Bartlett and weighted averages methods. The Anderson-Rubin method was eventually chosen as it produces factor scores that are uncorrelated. This was important as the factor scores were later used as predictors in a regression analysis. Having uncorrelated factor scores thus addressed concerns of multicollinearity.

Behavioral factors were analyzed using a cut-off point of 0.6. When oblique rotation was conducted, there was no correlation among factors above 0.32 . So varimax rotation was conducted and used as it had similar loadings as oblique rotation and is easier to interpret. Factor analysis results are displayed in Table 3.

After two iterations, all items loaded on a factor above an eigenvalue of one. The factor matrix yielded five factors with eigenvalues ranging from 1.70 to 1.44. The five factors accounted for over two-thirds of variance in the measure $(71.26 \%)$. The first factor 
Table 3 Behavioral factor loading matrix ${ }^{\mathrm{a}}$

\begin{tabular}{|c|c|c|c|c|c|}
\hline Factor & 1. Class Rep & 2. Non-classmates & 3. Staff & 4. Instructors & 5. Self \\
\hline Eigenvalue & 1.704 & 1.704 & 1.545 & 1.451 & 1.435 \\
\hline Percentage of variance & 15.49 & 15.49 & 14.05 & 13.19 & 13.05 \\
\hline Cumulative percentage of variance & 15.49 & 30.98 & 45.02 & 58.22 & 71.26 \\
\hline \multicolumn{6}{|l|}{ Variables } \\
\hline Class representative (academic issues) & .897 & & & & \\
\hline Class representative (admin issues) & .916 & & & & \\
\hline Other students (academic issues) & & .683 & & & \\
\hline Another person (academic issues) & & .800 & & & \\
\hline Work colleague (academic issues) & & .709 & & & \\
\hline Program head (admin issues) & & & .852 & & \\
\hline Admin staff (admin issues) & & & .875 & & \\
\hline Instructor (academic issues) & & & & .835 & \\
\hline Instructor (admin issues) & & & & .812 & \\
\hline Address it on my own (academic issues) & & & & & .828 \\
\hline Address it on my own (admin issues) & & & & & .838 \\
\hline
\end{tabular}

Extraction Method: Principal Component Analysis

Rotation Method: Varimax with Kaiser Normalization

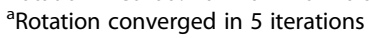

was about whether students sought help from the Class Representative for academic and administrative issues respectively. (A class representative was a student chosen by classmates to represent them to instructors and program staff). The second factor comprised of items about whether students sought help from non-classmates such as friends, family, work colleagues or students not in their class. The third factor comprised of items related to whether students sought help from institutional staff who were not instructors, for administrative issues. The fourth factor incorporated items about whether students sought help from instructors. The fifth item comprised of items related to whether students addressed their academic and administrative issues on their own.

It is important to note that survey items about "talking to classmates" did not load on any factors. This was despite the fact students nearly always turned to classmates for help as their number one option, to ask academic and administrative issues. When asked what do they do when they have a question about course content, students said their first choice was talking to classmates $(\mathrm{M}=3.62, \mathrm{SD}=0.60, N=433)$. (The Likert scale ranged from 1 $=$ Never to $4=$ Always). This was more than the next highest choice of "trying to address it on my own" ( $\mathrm{M}=3.26, \mathrm{SD}=0.73, N=429)$. Classmates were also the first choice when students were asked what they do when they sought help on an administrative question about a course or the program $(\mathrm{M}=3.28, \mathrm{SD}=0.88, N=434)$. This was slightly more than the next highest choice of talking to the instructor $(\mathrm{M}=3.19, \mathrm{SD}=0.91, N=435)$.

Classmates were such an important resource for students seeking help that responses to items about classmates violated the assumptions of normality. Over two-thirds of respondents $(67.9 \%)$ stated they "always" talk to classmates when they have a question about course content and no respondents $(0 \%)$ stated they "never" talk to classmates. Over half the respondents (50.5\%) stated they "always" turn to classmates when they have an administrative question about a course or the program and only $5.8 \%$ stated they "never" talk to classmates. Thus, there was a strong negative skew for responses 
about "talking to classmates". Given this ceiling effect, items about talking to classmates did not load on any factors. The lack of spread in responses meant that items about "talking to classmates" could not correlate with other items and thus were not in the factor model.

However, it was still possible to explore if students' behavior were related to their attitudes about why they communicate with people other than classmates for course purposes. To explore this relationship, factors scores from the attitudinal factor model were correlated with factors scores from the behavioral factor model. The results of the correlation matrix are indicated in Table 4.

Seven correlations were significant (all at $p<.01$ ) in the correlation matrix of attitudinal factors (i.e. about students attitudes to peers, instructors, courses, etc.) and behavioral factors (i.e. about their behavior for seeking help on academic and administrative issues). Five of the seven significant correlations were about whether students talked to instructors for academic and administrative issues (behavioral factor 4). Of these five, only two were moderately inter-correlated with attitudinal factors. There was a medium effect between students' perception of instructors (attitudinal factor 2) and whether they talked to instructors ( $r=.31$ or $9.7 \%$ of total variance explained). There was also a medium effect size between students' perceived sense of threat (attitudinal factor 6) and their tendency to seek help from the instructor about academic or administrative questions $(r=-.37$, representing $13.8 \%$ of total variance). These correlations make sense substantively. As students had a more positive perception of their instructors, they seemed more likely to talk to them about course and administrative issues. It also seems that the more threat students felt, the less inclined they were to talk to the instructor. There was a moderately strong relationship between the factor "perceived threat" with students' actual behavior of seeking help from instructors.

Two significant correlations were not about students' behavior with instructors. Respondents who were more independent were more likely to address their academic and administrative issues on their own $(r=.25$ or $6.3 \%$ of variance explained), according to the correlation of "Independence" (attitudinal factor 4) and "Working on one's own" (behavioral factor 5). This relationship seems straightforward enough, showing that those who prefer to learn on their own do indeed try to address academic and administrative issues on their own. The finding may also suggest correlations of attitudinal and correlation factors can make sense substantively and are not just random statistical correlations.

Table 4 Correlation of attitudinal and behavioral factors

\begin{tabular}{llllll}
\hline Attitudinal Factors & \multicolumn{5}{l}{ Behavioral Factors } \\
\cline { 2 - 6 } & 1. Class Rep & 2. Others non-classmates & 3. Resources & 4. Instructor & 5. On own \\
\hline 1. Peer Usefulness & $.140^{*}$ & .088 & .043 & .125 & .042 \\
2. Perception of instructors & -.011 & -.102 & .056 & $.312^{*}$ & .038 \\
3. Peer trust & -.089 & .034 & -.031 & $-.145^{*}$ & -.105 \\
4. Independence & -.054 & .007 & .011 & $.184^{*}$ & $.249^{*}$ \\
5. Perception of course & -.021 & -.014 & .051 & $-.150^{*}$ & -.015 \\
6. Threat & -.021 & -.019 & .025 & $-.372^{*}$ & .010 \\
\hline
\end{tabular}

*Significant at $p<.01$ 
The last significant correlation indicates that students who found it useful to work with classmates were likely to turn to their Class Representative for course and administrative issues (attitudinal factor 1 and behavioral factor 1). However, not too much can be read into this result as this was a fairly small effect, $r=.14$, explaining only $2.0 \%$ of total variance.

\section{Regression of attitude with behavior}

Multiple regression analysis was conducted to see if students' attitudes could be used to predict their behavior. Results of regression analysis depend upon the predictors selected and how they are entered into the model. Correlation analysis above indicated that nearly all attitudinal factors showed significance to one behavioral factor, "help from instructor". So the former factors were obvious choices as predictor variables with "help from instructor" as the criterion variable.

Hierarchical entry was used to enter five predictors into the model based on which predictors had the largest effect in the correlation analysis. Model one had one predictor, "perceived threat", model two had two predictors, "perceived threat" and "perception of instructors" etc., corresponding to the correlation analysis. Thus, there were five models in total. Of the five predictors, only two showed noticeable patterns in the partial regression plots. For the predictor "perceived threat" there is a noticeable negative relationship. So with less perceived threat students were more likely to ask the instructor about academic and administrative issues.

For the predictor "perception of instructor" there seemed to be a slight positive relationship with "help from instructor" as the criterion. No relationship was apparent in other partial regression plots.

The model would likely have at least two significant predictors; thus a Forward Stepwise analysis was used. This yielded similar results as the Hierarchical Entry method. The final regression results are indicated in Table 5 based on the Forward Stepwise analysis.

Three attitudinal factors were significant for predicting Help from Instructor, not two as expected from observing the partial regression plots. The strongest predictor was Perceived Threat $(\beta=-.29)$, followed by Perception of Instructor $(\beta=.23)$, and Independence $(\beta=.11)$. However, only the predictor "Perceived Threat" explained much variation in students' seeking help from instructors for academic and administrative issues. In the final model, Perceived Threat accounted for $13.8 \%$ of the variation in students' likelihood of seeking help from instructors. Perception of instructor accounted for an additional $4.9 \%$ of variation. Independence accounted for only $1.1 \%$ of variation. Thus, including "Perception of Instructor" and "Independence" as predictors explained only a small amount of variation in students' likelihood of talking to instructors. Nonetheless, they were statistically significant and thus kept in the final model.

The regression results indicate that attitudinal factors were useful for predicting students' communication behavior. Students' attitudes did predict their behavior for talking to instructors for academic and administrative help. In particular, students' perception of threat (i.e. concerns about looking stupid or other hesitations) was a moderate predictor of how likely they were to seek help from instructors.

\section{Discussion}

Factor analysis uncovered six latent dimensions of students' attitudes that may motivate or dissuade them from seeking help. These were: "usefulness of peers", "perception of 
Table 5 Students' attitudes that predict whether seek help from instructors

\begin{tabular}{|c|c|c|c|}
\hline & $B$ & SE B & $\beta$ \\
\hline \multicolumn{4}{|l|}{ Step 1} \\
\hline Constant & 0.02 & 0.05 & \\
\hline Threat & -0.36 & 0.05 & $-.37^{*}$ \\
\hline \multicolumn{4}{|l|}{ Step 2} \\
\hline Constant & 0.02 & 0.05 & \\
\hline Threat & -0.30 & 0.05 & $-.31^{*}$ \\
\hline Perception of instructors & 0.23 & 0.05 & $.23^{*}$ \\
\hline \multicolumn{4}{|l|}{ Step 3} \\
\hline Constant & 0.02 & & \\
\hline Threat & -0.28 & 0.05 & $-.29 *$ \\
\hline Perception of instructors & 0.22 & 0.05 & $.23^{*}$ \\
\hline Independence & 0.11 & 0.05 & $.11^{* *}$ \\
\hline
\end{tabular}

instructors", "trust of peers", "sense of independence", "perception of course" and "perceived sense of threat". Some attitudinal factors were related to whether students sought help from their instructors. "Perceived threat" was a factor that was negatively associated with why students did not talk to instructors for course and administrative purposes $(r=-.37, p<.01)$. This effect size was not inconsistent with findings from existing research. Karabenick and Knapp (1991) found a slightly lower effect size $(r=-.28, p<.001)$ and Kitsantas and Chow (2007) found a slightly higher effect size $(r=-.48, p<.001)$ for the association between students' "perceived sense of threat" and their formal help-seeking behavior. In this study, "perceived threat" was only correlated with students' behavior of asking instructors for help. This was because other resources (e.g. seeking help from the study support centre or program head) did not load with "talking to instructors" in the factor analysis. Nonetheless, the findings from this study reinforce that "perceived threat" seems to be an important negative motivation (i.e. deterrent) for students' interaction behavior.

Further still, this study yielded a model to predict how perceived threat affected students' interaction behavior with instructors outside of class. The model included three variables that predicted students' willingness to talk to instructors; "perceived threat", "perception of instructors", and "independence". However, only "perceived threat" accounted for a moderate amount of variation $(\beta=-.29)$.

It was a bit surprising that "perceived threat" would be the strongest predictor, and indeed finding, from this research. In the factor analysis "perceived threat" was a factor that loaded with only two items from the survey: an item on the relationship between a concern about looking stupid asking questions to instructors; and an item on hesitation of asking an instructor for help. Furthermore, "perceived threat" was the factor with the lowest eigenvalue of the six attitudinal factors that exceeded Kaiser's commonly accepted criterion of exceeding an eigenvalue of one. Nonetheless, it was a consistent and significant finding throughout the research.

Yet "perceived threat" is still a vague attribute of students. The items that loaded for this factor were two of several items included in the survey design to measure students' "perception of instructors". "Perceived threat" is an attribute that needs to be developed 
more intentionally and tested as a construct with more dimensions than it currently has. From this study, it is unclear if "perceived threat" is based on students' lack of selfefficacy (Bandura, 1997), or their concerns about being vulnerable to the organizational power that instructors represent, or some other issue. A richer construct needs to be created to measure dimensions of students' sense of threat.

More can be learned about "perceived threat" as a construct and predictor by also developing better criterion variables. It would be useful to analyze whether students sought help from classmates in lieu of instructors, due to perceived threat. The main research findings reinforce that, without a doubt, classmates were definitely a very important resource for students outside of class. Indeed, no item in the survey had a higher response rate. Help-seeking from classmates seems to be a very important learning strategy for students. Unfortunately, this behavior could not be used as a dependent variable because students turned to classmates for informal help-seeking so often, that there was not enough variance to conduct correlation or regression analysis. Future research would benefit from more varied behavioral items about students' seeking help from classmates. These items would also benefit from using a wider scale in a survey. A four point scale was used in this study, where the middle points of the Likert scale were not defined, allowing the scale to be a true ratio scale. Perhaps a wider scale, a six or seven point scale should be used, again without middle points being defined, to allow for more variability than the four-point scale used in this research.

\section{Conclusions and further research}

This study found that help-seeking continues to be an important learning strategy for students. They are seeking help from formal and informal resources. The decision to seek help is informed by attitudes and motivations that were identified and measured indirectly using constructs, which in this study have been called attributes. These indicate how students feel and behave. The research indicates that students' "perceived threat" is deterring students from approaching instructors for help. Educators need to acknowledge that students are using informal help-seeking options more than formal channels. Institutions need to consider ways to help foster and support these informal channels if there is a desire to scaffold students' help-seeking outside the classroom. An important question for educators now is how to reduce perceived threat of instructors. Or another approach may be about how to ensure that other help-seeking resources -classmates, social media resources, asynchronous tools -are reliable options.

For researchers, this study indicates that the topic of help-seeking warrants further research, especially as digital options continue to grow. It would be useful to specify which apps in particular students find more conducive for help-seeking, rather than asking more generally about text messaging, Facebook, etc. Furthermore, it may be useful to identify help-seeking habits for students in non-cohort based programs, where the use of digital technologies for help-seeking may differ. Non-cohort based study are increasingly the norms for many programs. If students are physically together less, as is the case in non-cohort programs, digital technologies may play a much more important role in their help-seeking behavior. As the demand for flexible models of education grows, the nature of cohort models will change or perhaps diminish. 
Finally, it would be useful to investigate if either formal or informal help-seeking improves student achievement. There was a conscious decision in this study to focus on student help-seeking attitudes and behaviors and not on how these related to student grades. It was more important to learn about student's learning strategies. However, it would be important to provide evidence that help-seeking is improving learning or outcomes.

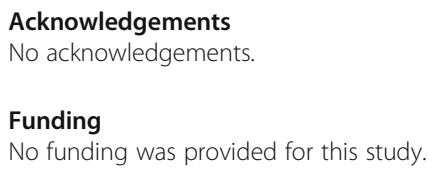

\section{Overlapping manuscript}

This manuscript is based on the thesis research done at Concordia University, Canada. None of the results in this manuscript have been published anywhere other than the thesis. Additionally, while the same data set was used as in the thesis, some of the data analysis and findings are different.

\section{Author's contributions}

The author is the full contributor to the research and writing of this study. The author read and approved the final manuscript.

\section{Ethics approval and consent to participate}

Ethical approval was received from the researcher's institution and the research site institutions to conduct this study.

\section{Consent for publication}

All participants in the study provided informed consent, as per the requirements of Research Ethics Review Board of the researcher's institution and research site institutions.

\section{Competing interests}

The author has no competing interests and no conflict of interest in the study.

\section{Publisher's Note}

Springer Nature remains neutral with regard to jurisdictional claims in published maps and institutional affiliations.

Received: 12 October 2017 Accepted: 28 March 2018

Published online: 10 May 2018

\section{References}

Aleven, V., Stahl, E., Schworm, S., Fischer, F., \& Wallace, R. (2003). Help-seeking and help design in interactive learning environments. Review of Educational Research, 73(3), 277-320.

Bandura, A. (1997). Self-efficacy: The exercise of control. New York: W. H. Freeman and Company.

Cheng, K., \& Tsai, C. (2011). An investigation of Taiwan University students' perceptions of online academic help- 562 seeking, and their web-based learning self-efficacy. The Internet and Higher Education, 14(3), 150-157.

Creswell, J. W. (2011). Educational research: Planning, conducting, and evaluating quantitative and qualitative research, (4th ed., ). Upper Saddle River: Pearson.

Dunn, K., Rakes, G., \& Rakes, T. (2014). Influence of academic self-regulation, critical thinking, and age on online graduate Students' academic help-seeking. Distance Education, 35(1), 75-89.

Karabenick, S. A. (2011). Classroom and technology-supported help seeking: The need for converging research paradigms. Learning and Instruction, 21(2), 290-296.

Karabenick, S. A., \& Knapp, J. R. (1988). Help-seeking and the need for academic assistance. Journal of Educational Psychology, 80, 406-408.

Karabenick, S. A., \& Knapp, J. R. (1991). Relationship of academic help seeking to the use of learning strategies and other instrumental achievement behavior in college students. Journal of Educational Psychology, 83(2), 221-230

Kitsantas, A., \& Chow, A. (2007). College students' perceived threat and preference of seeking help in traditional, distributed, and distance learning environments. Computers \& Education, 48, 383-395.

Koc, S., \& Liu, X. (2016). An investigation of graduate Students' help-seeking experiences, preferences and attitudes in online learning. Turkish Online Journal of Educational Technology., 15(3), 27-38.

Lissitz, R. W., \& Samuelsen, K. (2007). A suggested change in terminology and emphasis regarding validity and education. Educational Researcher, 36(8), 437-448.

Mahasneh, R., Sowan, A., \& Nassar, Y. (2012). Academic help-seeking in online and face-to-face learning environments. E-Learning and Digital Media, 9(2), 196-210.

McKeachie, W. (2006). Forward of S. Karabenick and R. Newman (Eds). Help seeking in academic settings: Goals, groups, and contexts. Mahwah: Lawrence Erlbaum Publishers. 
Nelson-Le Gall, S., \& Resnick, L. (1998). Help-seeking, achievement motivation, and the social practice of intelligence in school. In S. A. Karabenick (Ed.), Strategic help-seeking: Implications for learning and teaching, (pp. 39-60). Hillsdale: Erlbaum.

Newman, R. S. (1994). Adaptive help seeking: A strategy of self-regulated learning. In D. H. Schunk, \& B. J. Zimmerman (Eds.), Self-regulation of learning and performance: Issues and educational applications, (pp. 283-301). Hillsdale: Erlbaum.

Nicholson, S. (2002). Socialization in the "virtual hallway": Instant messaging in the asynchronous web-based distance education classroom. Internet and Higher Education, 5, 363-372.

Picciano, A. G. (2002). Beyond student perceptions: Issues of interaction, presence and performance in an online course. Journal of Asynchronous Learning Networks, 6(1), 21-40.

Pintrich, P. R., McKeachie, W. J., Smith, D. A. F., Doljanac, R., Lin, Y., Naveh-Benjamin, M., Crooks, T., \& Karabenick, S. A. (1988). Motivated strategies for learning questionnaire (MSLQ). Ann Arbor: National Center for Research to Improve Teaching and Learning. School of Education, University of Michigan.

Rovai, A. P. (2002). Development of an instrument to measure classroom community. Internet and Higher Education, 5(3), 197-211

Tabachnick, B., \& Fidell, L. (2012). Using multivariate statistics, (6th ed., ). Boston: Pearson.

Zimmerman, B. (1990). Self-regulated learning and academic achievement: An overview. Educational Psychologist, 25(1), $3-17$.

Submit your manuscript to a SpringerOpen ${ }^{\circ}$ journal and benefit from:

- Convenient online submission

- Rigorous peer review

- Open access: articles freely available online

- High visibility within the field

- Retaining the copyright to your article

Submit your next manuscript at $\gg$ springeropen.com 